\title{
An Improved State Space Average Model of Buck DC-DC Converter with all of the System Uncertainties
}

\author{
Mohammad Reza Modabbernia \\ Electrical Engineering Group, Technical and Vocational University, Rasht Branch. Rasht, Iran, \\ m_modabbernia@afr.ac.ir
}

\begin{abstract}
In this paper a complete state-space average model for the buck switching regulators is presented. The presented model includes the most of the regulator's parameters and uncertainties. In modeling, the load current is assumed to be unknown, and it is assumed that the inductor, capacitor, diode and regulator active switch are non ideal and they have a resistance in conduction condition. Some other non ideal effects look like voltage drop of conduction mode of the diode and active switch are also considered. This model can be used to design a precise and robust controller that can satisfy stability and performance conditions of the buck regulator. Also the effects of the boost parameters on the performance of the regulator can be shown easily with this model. After presenting the complete model, the buck converter Benchmark circuit is simulated in PSpice and its results are compared with our model simulation results in MATLAB. The results show the merit of our model.
\end{abstract}

Keywords: Buck regulator; average model; MATLAB; PSpice

\section{Introduction}

DC-DC Power converters are one of the standard components of switch mode power supplies (SMPS). They are used in personal computers, laptops, PDAs, office appliances, aircrafts, satellite communication equipment and DC motor starting circuits. The input of these converters is an unregulated DC voltage and its output is a regulated voltage [1].

In these converters, the switching capabilities of power devices are utilized to achieve the high efficiency. The non ideal nature of switches and their conduction mode resistance, and because the voltage and current can not suddenly become zero in switching times, there is some power loss on them. Due to these effects, the typical efficiency of such converters is actually about $70 \%$ to $95 \%$ [2].

The topology of DC-DC convertors consists of two linear (resistor, inductor and capacitor) and nonlinear (diode and active switch) parts. Because of the switching properties of the power elements, the operation of these convertors varies by time. Since these convertors are nonlinear and time variant, to design a linear controller, we need to find a small signal model basis of linearization of the state space average model about an appropriate operating point of it. The small signal analysis and controller design in frequency domain for DC-DC convertors are carried out by references [3-4].

Having a complete model which include all of the system parameters (such as turn-on resistance of the diode and active switch, resistance of inductor and capacitor, and unidentified load current that it can receive from the convertor) is the main step in designing a non conservative robust controller for Buck-boost convertors. Although work on buck state space average model began in the 1970 decade by Cuke and Middlebrook [5], a model that consists of the aforementioned parameters was not presented.

Alonge, Tomescue and Towati considered the boost regulator with inductance resistance, capacitance resistance and output current [6-8]. Benyakov only considers the capacitance resistance and output current regarding the said model and designs a robust controller. $\mathrm{He}$ mentioned the complexity of complete model and avoids presenting it in parametric form [9]. A linear model for Pulse Width Modulator (PWM) switch with an ideal diode and switch in

Received: December 21 ${ }^{\text {st }}, 2012$. Accepted: March $28^{\text {th }}, 2013$ 
both continuous and discontinuous current mode is presented in [10] and the effect of turn on resistance of diode and switch is considered in [11] for this model. An averaged model of boost regulator with consideration of capacitance and inductance resistances is demonstrated in [12]. Also, an average model to the PWM switch is presented by considering the diode and switch resistance and their voltage drop in discontinuous current mode without presenting the state space averaged model of regulator [13]. the state space average model of the boost regulator in the presence of all of the system uncertainties are presented in [14] and its P- $\Delta-\mathrm{K}$ represented are introduced in [15]. Finally, the open-loop audio susceptibility, input impedance and output impedance transfer functions of boost regulator in continuous conduction mode have been presented in [16] without forward Voltage drops of diode and active switch.

In this paper, on the basis of state space average method, we first obtain the state space equations of a Buck regulator in turn on and turn off modes by considering all the system parameters such as an inductor with resistance, a capacitor with resistance, a diode and switch on mode resistance and voltage drop, a load resistance and unidentified load current. Then the state equations are linearized around circuit operation point (input DC voltage and current versus output $\mathrm{DC}$ voltage). The coefficients of state space equations will therefore be dependent on the DC operating point in addition to the circuit parameters. At the end the duty cycle parameter "d" (control input) is extracted from the coefficients and introduced as an input.

Finally the buck converter Benchmark circuit is simulated in PSpice and its results are compared with our complete model simulation results in MATLAB. The simulations were done in three scenarios. The results are very closed to each other.

\section{Buck Regulator State equations for on-off time switching}

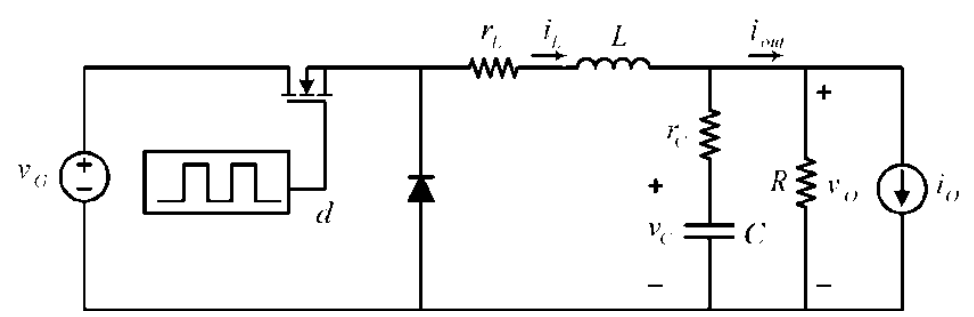

Figure 1. Buck regulator circuit

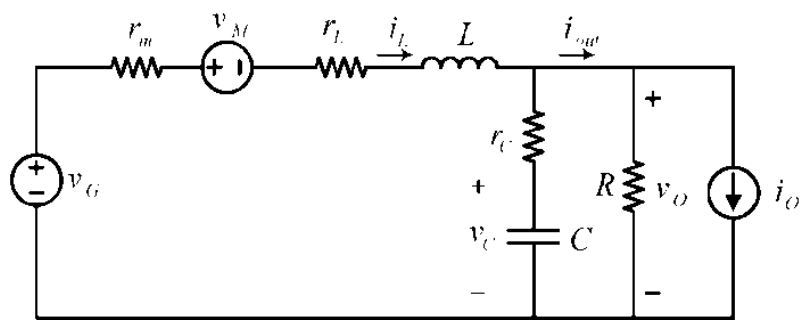

Figure 2. Equal circuit of Buck regulator in on times

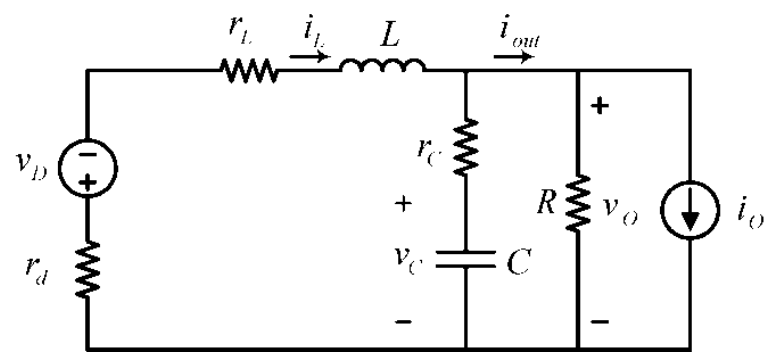

Figure 3. Equal circuit of Buck regulator in off times 
In modeling of the state space, the state variable which principally are the elements that store the energy of circuit or system (capacitance voltage and inductor current) have significant importance. In an electronic circuit, the first step in modeling is converting the complicated circuit, into basic circuit in which the circuit lows can be established.

In switching regulators, there are two regions; the on region and off region. The on time denoted by $d T$, and the off time is denoted by $d^{\prime} T=(1-d) T$, in which $T$ is the period of steady state output voltage. "Figure1" shows a buck switching regulator. The switch is turned on (off) by a pulse with a period of $T$ and its duty cycle is $d$. Therefore we can represent the equivalent circuit of the system in two on and off modes with $d T$ and $d^{\prime} T$ seconds respectively, by "Figure2" and "Figure3".

Consideration $i_{L}$ and $v_{C}$ as our state variables $\left(x=\left[i_{L} v_{C}\right]^{\prime}\right)$ and of writing the the KVL for the loops of "Figure2" we will have:

$$
\begin{aligned}
& \left\{\begin{array}{l}
\dot{x}=A_{1} x+B_{1} u \\
y=C_{1} x+D_{1} u
\end{array} \quad x=\left[\begin{array}{c}
i_{L} \\
v_{C}
\end{array}\right] \quad, \quad u=\left[\begin{array}{c}
v_{G} \\
i_{O} \\
v_{M} \\
v_{D}
\end{array}\right] \quad, \quad y=\left[\begin{array}{c}
v_{O} \\
i_{\text {out }} \\
i_{L}
\end{array}\right]\right. \\
& A_{1}=\left[\begin{array}{cc}
\frac{K_{1}}{\left(R+r_{C}\right) L} & \frac{-R}{\left(R+r_{C}\right) L} \\
\frac{R}{\left(R+r_{C}\right) L} & \frac{-1}{\left(R+r_{C}\right) C}
\end{array}\right] \\
& \text { where } K_{1}=-\left(R r_{L}+R r_{C}+R r_{m}+r_{C} r_{L}+r_{m} r_{C}\right) \\
& B_{1}=\left[\begin{array}{cccc}
\frac{1}{L} & \frac{R r_{C}}{\left(R+r_{C}\right) C} & \frac{-1}{L} & 0 \\
0 & \frac{-R}{\left(R+r_{C}\right) C} & 0 & 0
\end{array}\right], C_{1}=\left[\begin{array}{ccc}
\frac{R r_{C}}{R+r_{C}} & \frac{R}{R+r_{C}} \\
\frac{r_{C}}{R+r_{C}} & \frac{1}{R+r_{C}} \\
1 & 0
\end{array}\right], D_{1}=\left[\begin{array}{cccc}
0 & \frac{-R r_{C}}{R+r_{C}} & 0 & 0 \\
0 & \frac{R}{R+r_{C}} & 0 & 0 \\
0 & 0 & 0 & 0
\end{array}\right]
\end{aligned}
$$

Also for off time or $d^{\prime} T$ seconds the KVL equations from "Figure3" are given by “(2)".

$$
\left\{\begin{array}{l}
\dot{x}=A_{2} x+B_{2} u \\
y=C_{2} x+D_{2} u
\end{array} \quad x=\left[\begin{array}{c}
i_{L} \\
v_{c}
\end{array}\right] \quad, \quad u=\left[\begin{array}{c}
v_{G} \\
i_{O} \\
v_{M} \\
v_{D}
\end{array}\right] \quad, \quad y=\left[\begin{array}{c}
v_{O} \\
i_{\text {out }} \\
i_{L}
\end{array}\right]\right.
$$




$$
\begin{aligned}
& A_{2}=\left[\begin{array}{cc}
\frac{K_{2}}{L\left(R+r_{C}\right)} & \frac{-R}{L\left(R+r_{C}\right)} \\
\frac{R}{\left(R+r_{C}\right) C} & \frac{-1}{\left(R+r_{C}\right) C}
\end{array}\right] \\
& \text { where } K_{2}=-\left(R r_{C}+R r_{L}+r_{L} r_{C}+R r_{d}+r_{d} r_{C}\right)
\end{aligned}
$$

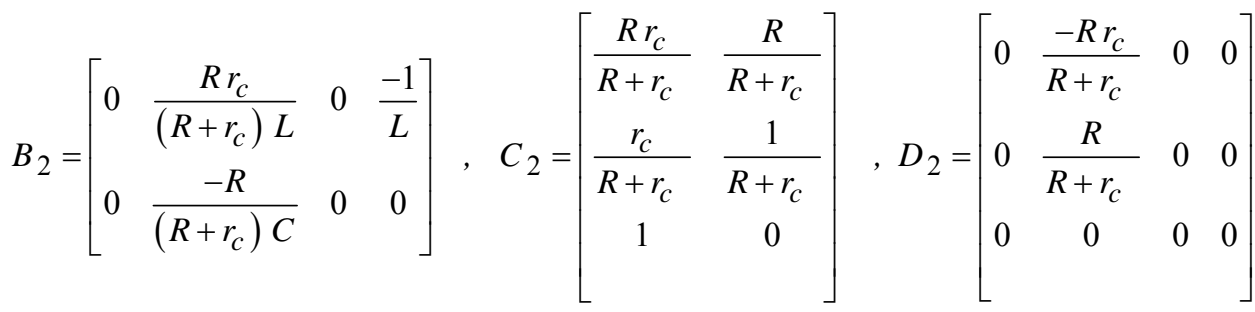

The set of state equations "(1)" and "(4)" shows the state of buck regulator in the on and off time of switch. We can combine these two set of equations as following [6,7]:

$$
\left\{\begin{array}{l}
\dot{x}=A_{P} x+B_{P} u \\
v_{O}=C_{P} x+D_{P} u
\end{array}, \quad\left\{\begin{array}{l}
A_{P}=A_{1} d+A_{2}(1-d) \\
B_{p}=B_{1} d+B_{2}(1-d)
\end{array}, \quad\left\{\begin{array}{l}
C_{p}=C_{1} d+C_{2}(1-d) \\
D_{p}=D_{1} d+D_{2}(1-d)
\end{array}\right.\right.\right.
$$

By substituting equations “(1)" to "(6)" we can obtain coefficients of $A_{P}$ to $D_{P}$.

\section{A. Linearization of state equations around operating point}

$$
\begin{aligned}
& A_{P}=\left[\begin{array}{cc}
\frac{K_{1}\left(1-d^{\prime}\right)+K_{2} d^{\prime}}{L\left(R+r_{C}\right)} & \frac{-R}{L\left(R+r_{C}\right)} \\
\frac{R}{\left(R+r_{C}\right) C} & \frac{-1}{\left(R+r_{C}\right) C}
\end{array}\right] \quad, \quad B_{P}=\left[\begin{array}{cccc}
\frac{1-d^{\prime}}{L} & \frac{R r_{C}}{\left(R+r_{C}\right) L} & \frac{-1+d^{\prime}}{L} & \frac{-d^{\prime}}{L} \\
0 & \frac{-R}{\left(R+r_{C}\right) C} & 0 & 0
\end{array}\right] \\
& C_{P}=\left[\begin{array}{cc}
\frac{R r_{C}}{R+r_{C}} & \frac{R}{R+r_{C}} \\
\frac{r_{C}}{R+r_{C}} & \frac{1}{R+r_{C}} \\
1 & 0
\end{array}\right] \quad, \quad D_{P}=\left[\begin{array}{cccc}
0 & \frac{-R r_{C}}{R+r_{C}} & 0 & 0 \\
0 & \frac{R}{R+r_{C}} & 0 & 0 \\
0 & 0 & 0 & 0
\end{array}\right]
\end{aligned}
$$

The results presented in section 2 are acceptable when the circuit time constant is much larger than the period of switching. . If the duty cycle be a constant value $(d=D)$, the state equations in "(7)" will become linear. For regulating the voltage on a desired value, we have to change the value of $D$ by a controller. In general, the state equations of "(7)" are nonlinear and we have to linear them around an operating point $(D)$. When the system is in equilibrium 
and the duty cycle is on its nominal value $(D)$, then we can obtain the system state values in equilibrium points $\left(x=\left[I_{L} V_{C}\right]^{\prime}\right)$ and the DC output voltage $\left(V_{O}\right)$.

$$
\begin{gathered}
\dot{x}=A_{P} x+B_{p} u=0 \Rightarrow X=-A_{P}^{-1} B_{p}\left[\begin{array}{c}
V_{G} \\
I_{O} \\
V_{M} \\
V_{D}
\end{array}\right]=\left[\begin{array}{c}
I_{L} \\
V_{C}
\end{array}\right] \\
X=\left[\begin{array}{c}
\frac{\left(R+r_{c}\right)\left(1-D^{\prime}\right)}{\Delta} V_{G}+\frac{R\left(R+r_{C}\right)}{\Delta} I_{O}-\frac{\left(R+r_{c}\right)\left(1-D^{\prime}\right)}{\Delta} V_{M}-\frac{\left(R+r_{c}\right) D^{\prime}}{\Delta} V_{D} \\
\frac{R\left(R+r_{c}\right)\left(1-D^{\prime}\right)}{\Delta} V_{G}+\frac{R^{2} r_{c}+R^{3}-R \Delta}{\Delta} I_{O}-\frac{R\left(R+r_{c}\right)\left(1-D^{\prime}\right)}{\Delta} V_{M}-\frac{R\left(R+r_{c}\right) D^{\prime}}{\Delta} V_{D}
\end{array}\right] \\
\Delta=K_{1}+\left(K_{2}-K_{1}\right)+R^{2}=\left[R^{2}-R r_{C}+\left(r_{L}+r_{m}\right)\left(R+r_{C}\right)\right]+\left[\left(r_{m}-r_{d}\right)\left(R+r_{C}\right)\right] D^{\prime}
\end{gathered}
$$

and

$$
Y=C_{p} X+D_{p} U \quad, \quad Y=\left[\begin{array}{c}
V_{O} \\
I_{\text {out }} \\
I_{L}
\end{array}\right]
$$

where $_{V_{O}}=\frac{R\left(R+r_{C}\right)\left(1-D^{\prime}\right)}{\Delta} V_{G}+\frac{R^{2}\left(R+r_{C}\right)-R \Delta}{\Delta} I_{O}-\frac{R\left(R+r_{C}\right)\left(1-D^{\prime}\right)}{\Delta} V_{M}-\frac{R\left(R+r_{C}\right) D^{\prime}}{\Delta} V_{D}$

$$
I_{L}=I_{\text {out }}=\frac{\left(R+r_{C}\right)\left(1-D^{\prime}\right)}{\Delta} V_{G}+\frac{R\left(R+r_{C}\right)}{\Delta} I_{O}-\frac{\left(R+r_{C}\right)\left(1-D^{\prime}\right)}{\Delta} V_{M}-\frac{\left(R+r_{C}\right) D^{\prime}}{\Delta} V_{D}
$$

Finally for linearization of the system, on basis of classic method, we divided our variables into two parts. The first part is static part (a fixed DC level), and the second part is a small amplitude that modulates the DC level. On this basis, the variables in the state equations can be defined as follows:

$$
\left\{\begin{array} { l } 
{ x ( t ) = X + \hat { x } } \\
{ d ( t ) = D + \hat { d } }
\end{array} \quad \left\{\begin{array}{l}
u(t)=U+\hat{u} \\
v_{o}(t)=V_{O}+\hat{v}_{o}
\end{array}\right.\right.
$$

In which $V_{O}, x=\left[\begin{array}{ll}i_{L} & v_{C}\end{array}\right]^{\prime}$ and $U=\left[\begin{array}{llll}V_{G} & I_{G} & V_{M} & V_{D}\end{array}\right]^{\prime}$ are the nominal values of the DC output voltage, state variables and no controllable inputs respectively. Each of them has 
small variations (denoted with ${ }^{\wedge}$ ) around nominal values. By substituting equations "(15)” in "(7)" and assumed that the duty cycle $d$ has also variation $\hat{d}(d=D+\hat{d})$, we will have

$$
\left\{\begin{array}{l}
\dot{X}+\dot{\hat{x}}=A_{P} \hat{x}+B_{P} \hat{u}+\left[\left(A_{1}-A_{2}\right) X+\left(B_{1}-B_{2}\right) U\right] \hat{d}+\dot{X} \\
\dot{V}_{O}+\dot{\hat{v}}_{O}=C_{P} \hat{x}+D_{P} \hat{u}+\left[\left(C_{1}-C_{2}\right) X+\left(D_{1}-D_{2}\right) U\right] \hat{d}+\dot{V}_{O}
\end{array}\right.
$$

or

$$
\left\{\begin{array} { l } 
{ \dot { \hat { x } } = A _ { P } \hat { x } + B _ { P } \hat { u } + E \hat { d } } \\
{ \dot { \hat { v } } _ { o } = C _ { P } \hat { x } + D _ { P } \hat { u } + F \hat { d } }
\end{array} \quad \left\{\begin{array}{l}
E=\left(A_{1}-A_{2}\right) X+\left(B_{1}-B_{2}\right) U \\
F=\left(C_{1}-C_{2}\right) X+\left(D_{1}-D_{2}\right) U
\end{array}\right.\right.
$$$$
E=\left[\begin{array}{c}
\frac{\left(r_{d}-r_{m}\right)\left(R+r_{c}\right)\left(1-D^{\prime}\right)+\Delta}{L \Delta} V_{G}+\frac{R\left(r_{d}-r_{m}\right)\left(R+r_{c}\right)}{L \Delta} I_{O} \\
-\frac{\left(r_{d}-r_{m}\right)\left(R+r_{c}\right)\left(1-D^{\prime}\right)+\Delta}{L \Delta} V_{M}-\frac{\left(r_{d}-r_{m}\right)\left(R+r_{c}\right) D^{\prime}-\Delta}{L \Delta} V_{D} \\
0
\end{array}\right]
$$

$F=\left(C_{1}-C_{2}\right) X+\left(D_{1}-D_{2}\right) U=0$ and $\Delta$ is defined by "(11)".

\section{State space average model}

An important point in the set equations in that $A_{P}$ and $C_{P}$ are related to $d^{\prime}=1-d$. Since $d=D+\hat{d}$ then $A_{P}$ and $C_{P}$ are related to $\hat{d}$. It can be shown that with good approximation this dependence is negligible. By sub situation $A_{P}, B_{P}, C_{P}$, and $D_{P}$ by their equivalents in term of $d, A_{1}, B_{1}, C_{1}$ and $D_{1}$ we will obtain:

$$
\left\{\begin{array}{l}
\dot{\hat{x}}=\left[A_{1} d+A_{2}(1-d)\right] \hat{x}+\left[B_{1} d+B_{2}(1-d)\right] \hat{u}+E \hat{d} \\
\hat{y}=\left[C_{1} d+C_{2}(1-d)\right] \hat{x}+\left[D_{1} d+D_{2}(1-d)\right] \hat{u}+F \hat{d}
\end{array}\right.
$$

$d=D+\hat{d}$ therefore, we have for the first above equation.

$\dot{\hat{x}}=\left[A_{1} D+A_{2}(1-D)\right] \hat{x}+\left[B_{1} D+B_{2}(1-D)\right] \hat{u}+E \hat{d}+\left(A_{1}-A_{2}\right) \hat{d} \hat{x}+\left(B_{1}-B_{2}\right) \hat{d} \hat{u}$ 
Since $\hat{d}, \hat{u}$ and $\hat{x}$ denotes small variation of the duty cycle, input and state of system respectively, their product is very small and we can neglect terms such as $\hat{d} \hat{x}$ and $\hat{d} \hat{u}$.

$$
\dot{\hat{x}}=A \hat{x}+B \hat{u}+E \hat{d}
$$

In the same manner, the effect of $\hat{d} \hat{x}$ and $\hat{d} \hat{u}$ in second equation of "(20)" is negligible. Therefore we can represent the buck regulator state equations like this:

$$
\begin{array}{ll}
\left\{\begin{array}{ll}
\hat{\hat{x}}=A \hat{x}+B \hat{u}+E \hat{d} \\
\dot{\hat{y}}=C \hat{x}+D \hat{u}+F \hat{d}
\end{array}, \quad x=\left[\begin{array}{c}
i_{L} \\
v_{C}
\end{array}\right], \quad u=\left[\begin{array}{c}
v_{G} \\
i_{O} \\
v_{M} \\
v_{D}
\end{array}\right] \quad, \quad y=\left[\begin{array}{c}
v_{O} \\
i_{\text {out }} \\
i_{L}
\end{array}\right]\right. \\
A=\left[\begin{array}{cc}
\frac{K_{1}\left(1-D^{\prime}\right)+K_{2} D^{\prime}}{L\left(R+r_{C}\right)} & \frac{-R}{L\left(R+r_{C}\right)} \\
\frac{R}{\left(R+r_{C}\right) C} & \frac{-1}{\left(R+r_{C}\right) C}
\end{array}\right] \quad, \quad B=\left[\begin{array}{cccc}
\frac{1-D^{\prime}}{L} & \frac{R r_{C}}{\left(R+r_{C}\right) L} & \frac{-1+D^{\prime}}{L} & \frac{-D^{\prime}}{L} \\
0 & \frac{-R}{\left(R+r_{C}\right) C} & 0 & 0
\end{array}\right] \\
C=\left[\begin{array}{cc}
\frac{R r_{C}}{R+r_{C}} \frac{R}{R+r_{C}} \\
\frac{r_{C}}{R+r_{C}} \frac{1}{R+r_{C}} \\
1
\end{array}\right] \quad D=\left[\begin{array}{cccc}
0 & \frac{-R r_{C}}{R+r_{C}} & 0 & 0 \\
0 & \frac{R}{R+r_{C}} & 0 & 0 \\
0 & 0 & 0 & 0
\end{array}\right]
\end{array}
$$

$K_{1}, K_{2}, E$ and $F$ are represented with equations “(2)”, “(5)”, “(18)” and "(19)” respectively.

\section{Simulation with PSpice and matlab}

To show the accuracy of our complete model, the benchmark circuit of buck regulator [1] was simulated with PSpice and then its consequences were compared with the simulation results of presented model in MATLAB. "Figure4", "Figure5" and "Figure6" show the buck benchmark circuit in PSpice and its equivalent model in SIMULINK respectively. The simulations were performed under the following conditions: $L=5 \mu \mathrm{H}, C=100 \mu \mathrm{F}$, $R=0.5 \Omega$ and $V_{G}=8 \mathrm{~V}$. The switching frequency is $100 \mathrm{kHz}$ and various cases of simulation have been considered. In all cases, there is a $1 \mathrm{~V}$ rise in the input voltage at $1 \mathrm{mS}$ and $1 \mathrm{~A}$ change is appeared in load current at $2 \mathrm{mS}$. These are due to show the merit of our proposed model in response to input and output disturbances. 


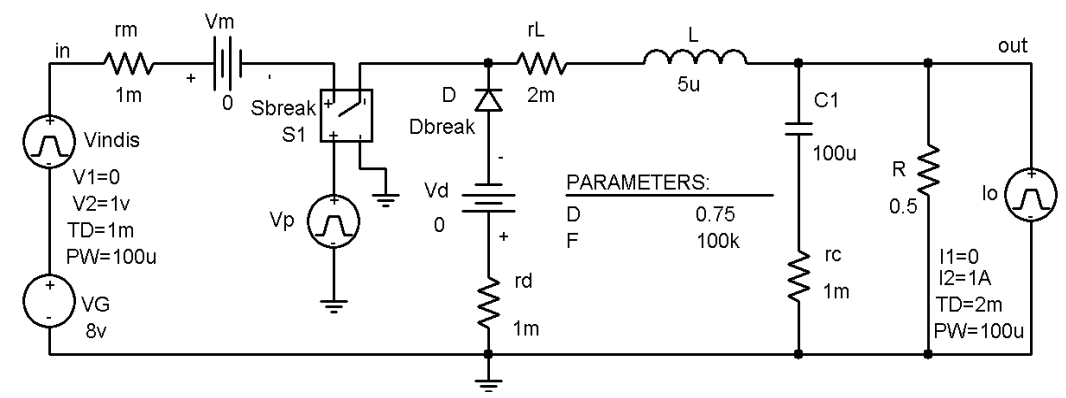

Figure 4. The buck benchmark circuit in PSpice

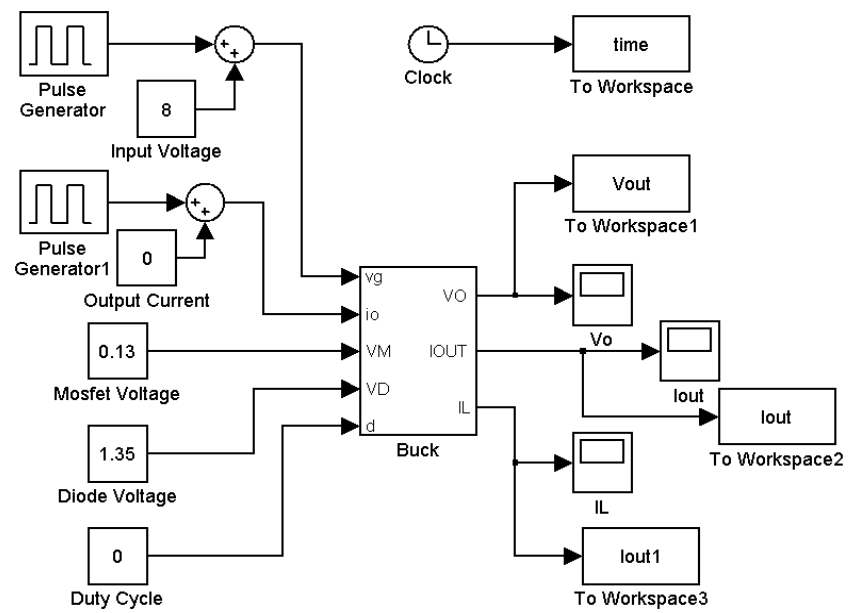

Figure 5. The buck benchmark circuit in SIMULINK

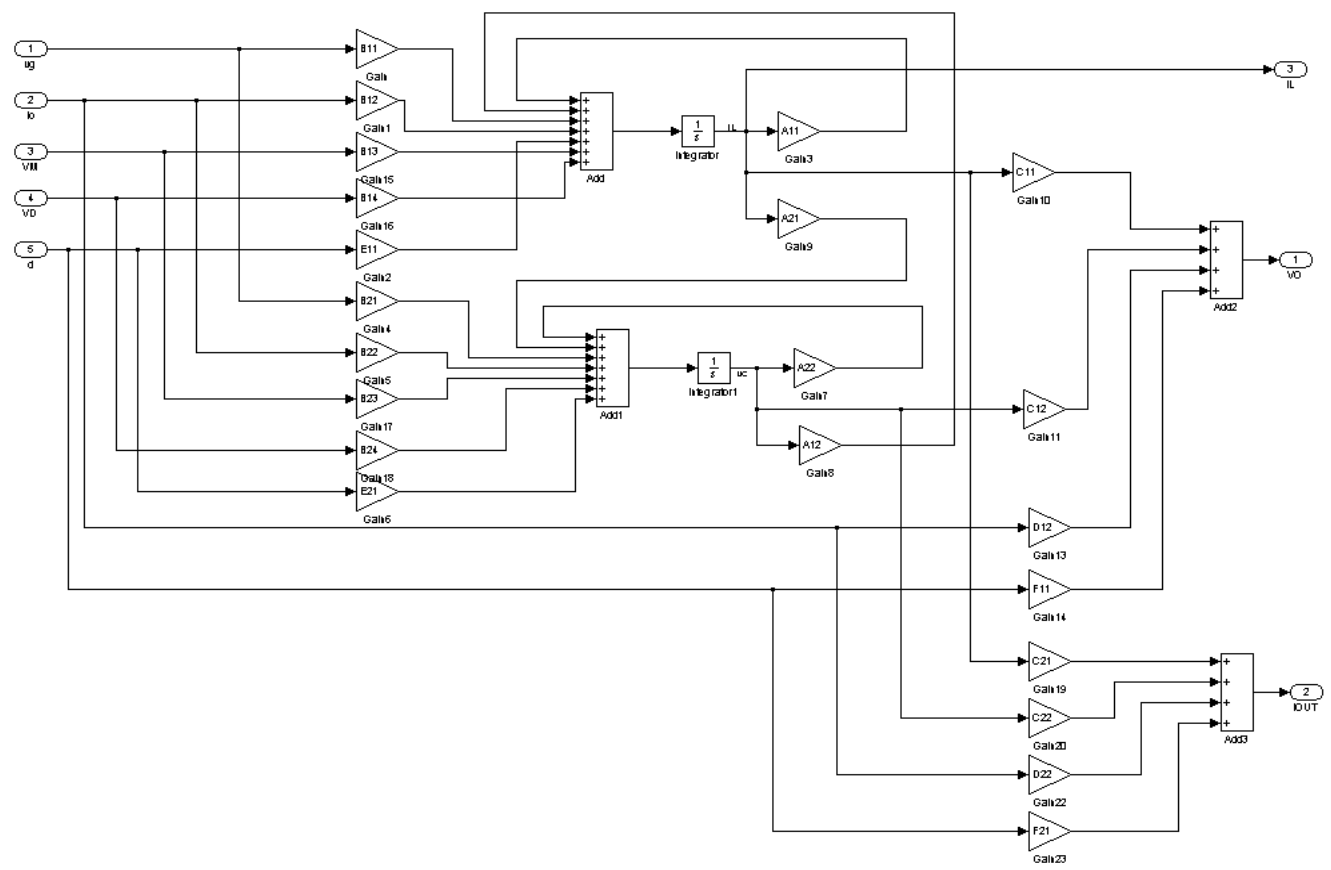

Figure 6. Equivalent model of Buck regulator in SIMULINK 
A. Ideal Case: Switches with no forward voltage drop and minimum on state resistance The simulation results of PSpice and MATLAB accompanied by $r_{m}=r_{d}=r_{C}=1 \mathrm{~m} \Omega$, $r_{L}=10 \mathrm{~m} \Omega$ and $V_{M}=0 \mathrm{~V}$ were shown by "Figure7" and "Figure8" respectively. Based on PSpice simulation, we assume that the diode conducting voltage drop in MATLAB is $0.1 \mathrm{~V}$. Table I compare the results of two simulations with each other. The PSpice and MATLAB output Voltage are $5.9345 \mathrm{~V}$ and $5.939 \mathrm{~V}$ respectively. They are so close to the ideal output value $\left(V_{O}=D \times V_{G}=0.75 \times 8=6 \mathrm{~V}\right)$. The over-shoots of two simulations are so mach with each other in response to the input voltage and load current disturbances. In this case, the system is under damp condition.

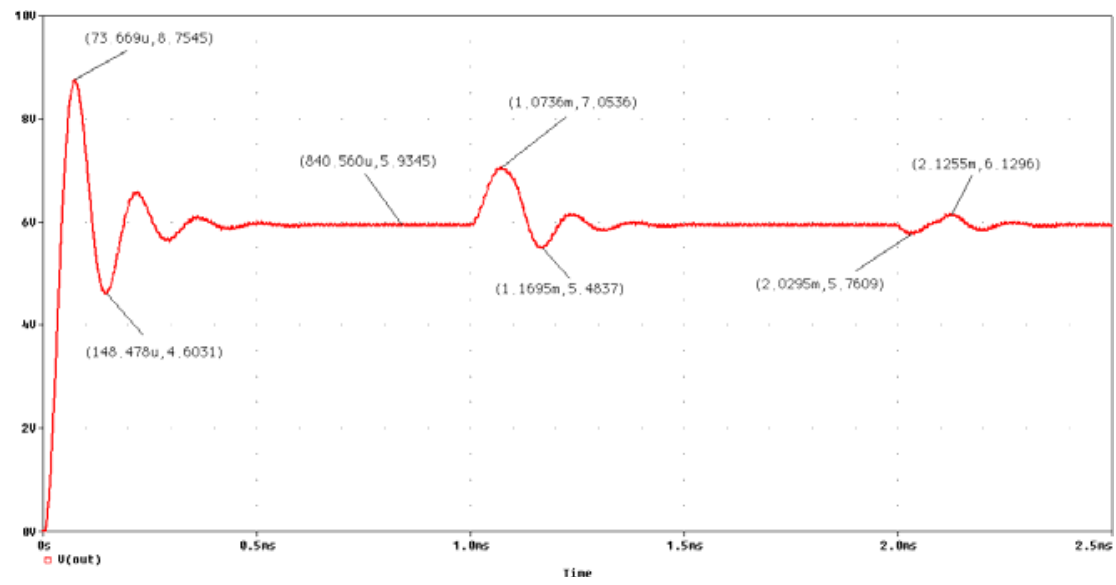

Figure 7. Output voltage with $V_{D}=0.1 \mathrm{~V}$ and $V_{M}=0 \mathrm{~V}$ in PSpice

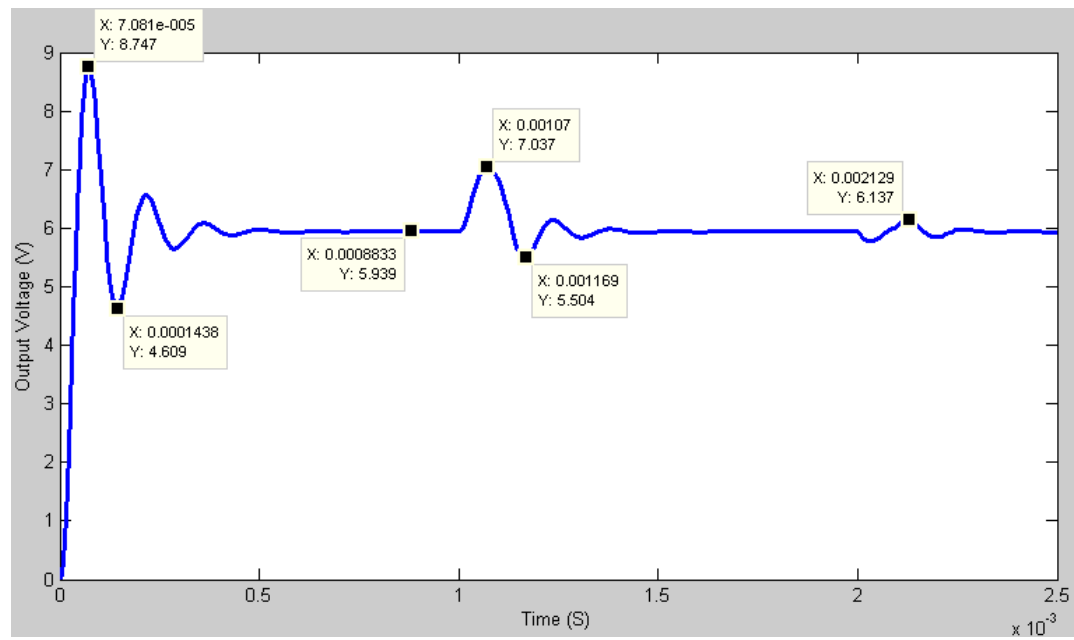

Figure 8. Output voltage with $V_{D}=0.1 \mathrm{~V}$ and $V_{M}=0 \mathrm{~V}$ in MATLAB

Output Voltage Results of PSpice and Matlab Simulation with $V_{D}=0.1 \mathrm{~V}$ and $V_{M}=0 \mathrm{~V}$

\begin{tabular}{|c|c|c|c|c|}
\hline & $\begin{array}{c}\text { Steady State } \\
\text { Value }\end{array}$ & $\begin{array}{c}\text { Overshoot } \\
\text { Peak Value }\end{array}$ & $\begin{array}{c}\text { Input Voltage } \\
\text { Disturbance }\end{array}$ & $\begin{array}{c}\text { Load } \\
\text { Disturbance }\end{array}$ \\
\hline PSpice & $5.939 \mathrm{~V}$ & $8.7545 \mathrm{~V}$ & $7.0536 \mathrm{~V}$ & $6.129 \mathrm{~V}$ \\
\hline MATLAB & $5.939 \mathrm{~V}$ & $8.847 \mathrm{~V}$ & $7.037 \mathrm{~V}$ & $6.137 \mathrm{~V}$ \\
\hline
\end{tabular}


B. Non Ideal Case: Active Switch with $V_{M}=0.5 \mathrm{~V}$, Diode with $V_{D}=0.8 \mathrm{~V}$, $r_{m}=r_{d}=r_{C}=0.1 \Omega$ and $r_{L}=0.2 \Omega$

The results of PSpice and MATLAB simulation with $V_{M}=0.5 \mathrm{~V}, V_{D}=0.8 \mathrm{~V}$, $r_{m}=r_{d}=r_{C}=0.1 \Omega$ and $r_{L}=0.2 \Omega$ have been shown in "Figure 9" and "Figure 10".

With these values, the system is over damp and there is no overshoot in output voltage. The table II shows these simulation results and compares them.

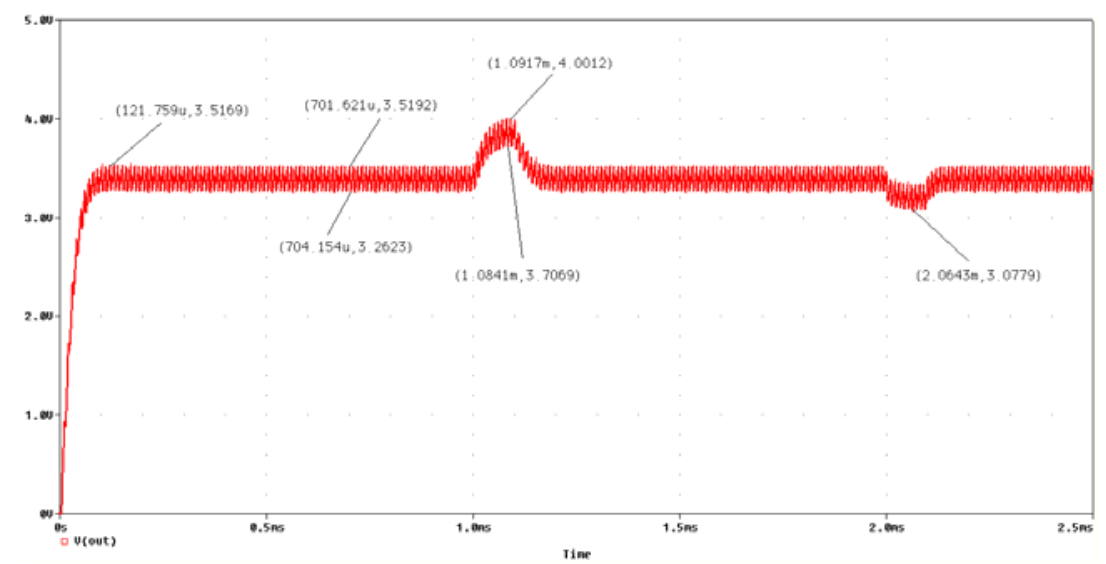

Figure 9. Output voltage with $V_{D}=0.8 \mathrm{~V}, V_{M}^{\text {rime }}=0.5 \mathrm{~V}, r_{m}=r_{d}=r_{C}=0.1 \Omega$ and $r_{L}=0.2 \Omega$ in PSpice

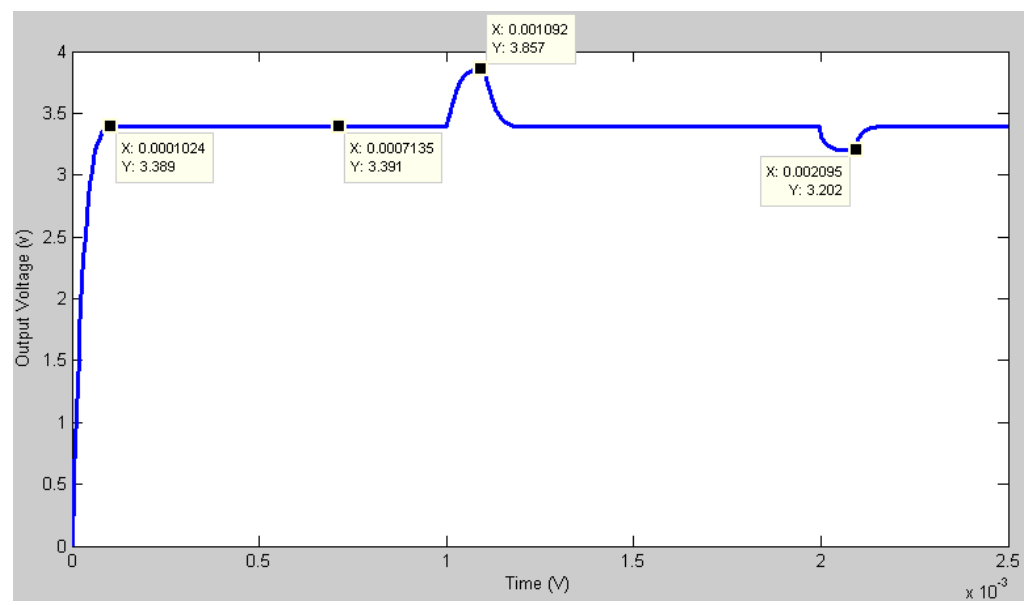

Figure 10. Output voltage with $V_{D}=0.8 \mathrm{~V}, V_{M}=0.5 \mathrm{~V}, r_{m}=r_{d}=r_{C}=0.1 \Omega$ and

$$
r_{L}=0.2 \Omega \text { in MATLAB }
$$

Table 2. Output Voltage Results of PSpice and Matlab Simulation with $V_{D}=0.8 \mathrm{~V}$,

\begin{tabular}{|c|c|c|c|c|}
\multicolumn{5}{c|}{$V_{M}=0.5 \mathrm{~V}, r_{m}=r_{d}=r_{C}=0.1 \Omega$ and $r_{L}=0.2 \Omega$} \\
\hline & $\begin{array}{c}\text { Steady State } \\
\text { Value }\end{array}$ & $\begin{array}{c}\text { Overshoot Peak } \\
\text { Value }\end{array}$ & $\begin{array}{c}\text { Input Voltage } \\
\text { Disturbance }\end{array}$ & Load Disturbance \\
\hline PSpice & $\begin{array}{c}\text { Between 3.26V } \\
\text { and 3.519V }\end{array}$ & Over damp & $\begin{array}{c}\text { Between 3.7V and } \\
4.01 \mathrm{~V}\end{array}$ & $3.0779 \mathrm{~V}$ \\
\hline MATLAB & $3.391 \mathrm{~V}$ & Over damp & $3.857 \mathrm{~V}$ & $3.202 \mathrm{~V}$ \\
\hline
\end{tabular}




\section{The Effects of Active Switch and Diode On State Resistances}

To show the effects of on state resistance and forward voltage drop of diode and mosfet, it is assumed that the parasitic resistances of inductance and capacitance are negligible $\left(r_{L}=2 \mathrm{~m} \Omega, r_{C}=1 \mathrm{~m} \Omega\right)$ and input voltage is half $\left(V_{G}=4 \mathrm{~V}\right)$. The simulation results accompanied by $r_{d}=r_{m}=0.1 \Omega, V_{D}=0.8 \mathrm{~V}$ and $V_{M}=0.5 \mathrm{~V}$ have been shown by "Figure 11 " and "Figure12" in PSpice and MATLAB respectively. The table III shows these simulation results and compares them.

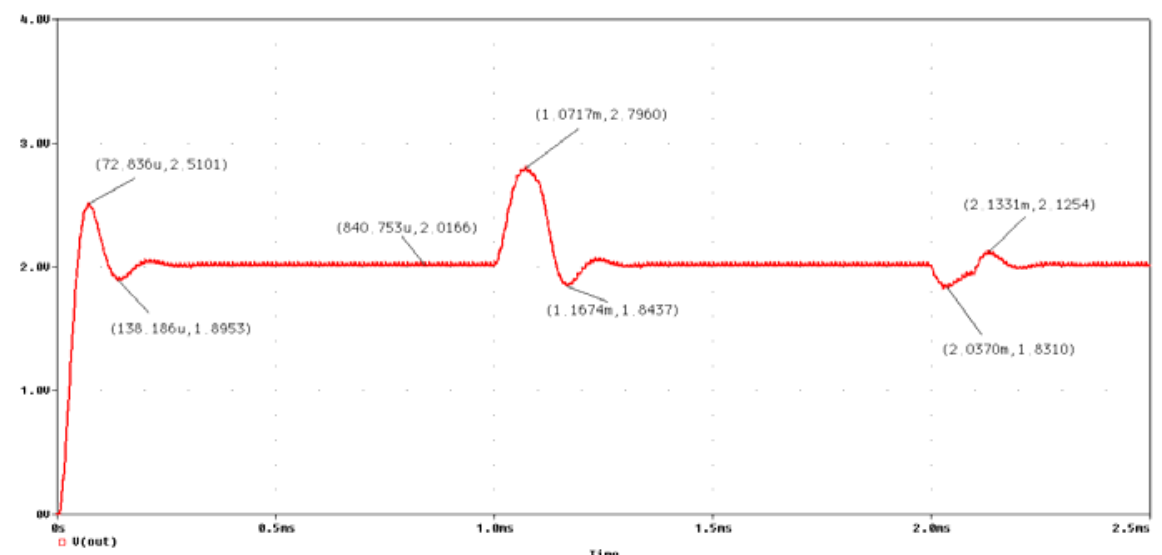

Figure 11. Output voltage with $V_{G}=4 \mathrm{~V}, V_{D}=0.8 \mathrm{~V}, V_{M}=0.5 \mathrm{~V}, r_{m}=r_{d}=0.1 \Omega$,

$$
r_{C}=1 \mathrm{~m} \Omega \text { and } r_{L}=2 \mathrm{~m} \Omega \text { in PSpice }
$$

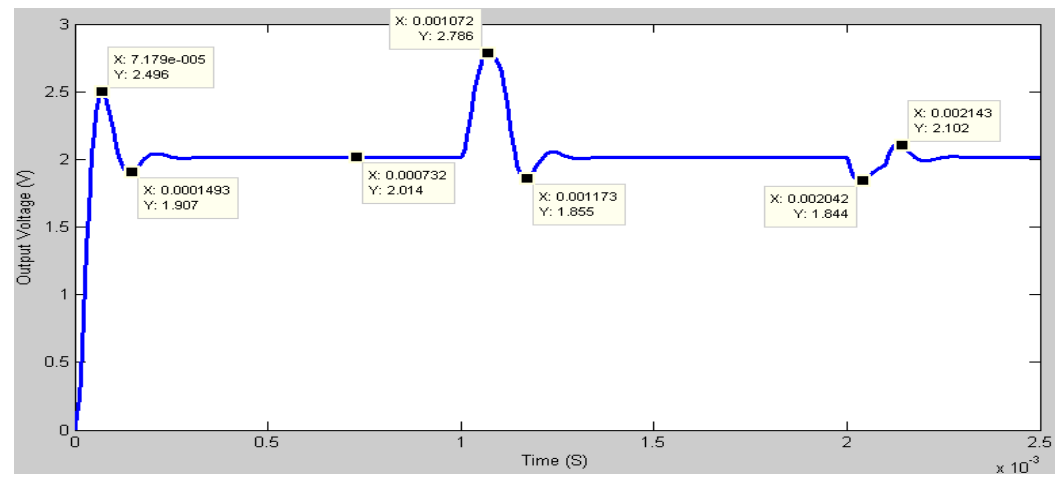

Figure 12. Output voltage with $V_{G}=4 \mathrm{~V}, V_{D}=0.8 \mathrm{~V}, V_{M}=0.5 \mathrm{~V}, r_{m}=r_{d}=0.1 \Omega$

$$
, r_{C}=1 \mathrm{~m} \Omega \text { and } r_{L}=2 \mathrm{~m} \Omega \text { in MATLAB. }
$$

Table 3. Output Voltage Results of PSpice and Matlab Simulation with $V_{G}=4 \mathrm{~V}$,

$V_{D}=0.8 \mathrm{~V}, V_{M}=0.5 \mathrm{~V}, r_{m}=r_{d}=0.1 \Omega, r_{C}=1 \mathrm{~m} \Omega$ and $r_{L}=2 \mathrm{~m} \Omega$

\begin{tabular}{|c|c|c|c|c|}
\hline & $\begin{array}{c}\text { Steady State } \\
\text { Value }\end{array}$ & $\begin{array}{c}\text { Overshoot } \\
\text { Peak Value }\end{array}$ & $\begin{array}{c}\text { Input Voltage } \\
\text { Disturbance }\end{array}$ & $\begin{array}{c}\text { Load } \\
\text { Disturbance }\end{array}$ \\
\hline PSpice & $2.0166 \mathrm{~V}$ & $2.51 \mathrm{~V}$ & $2.796 \mathrm{~V}$ & $1.831 \mathrm{~V}$ \\
\hline MATLAB & $2.014 \mathrm{~V}$ & $2.496 \mathrm{~V}$ & $2.786 \mathrm{~V}$ & $1.844 \mathrm{~V}$ \\
\hline
\end{tabular}




\section{Real Case: Simulation with IRF540Mosfet and BAV102 Diode}

If an IRF540 mosfet transistor and BAV102 diode were considered instead of active switch and ideal diode respectively, there will be $0.57 \mathrm{~V}$ and $3 \mathrm{~V}$ voltage drop on the drain-source of transistor and anode-cathode of diode in PSpice simulation respectively. In this situation, the on state resistances of mosfet and diode are $0.083 \Omega$ and $0.031 \Omega$ respectively. The MATLAB simulation was done with these values. The results of PSpice and MATLAB simulation have been shown in "Figure13" and "Figure 14" respectively. The table 4 shows these simulation results and compares them.

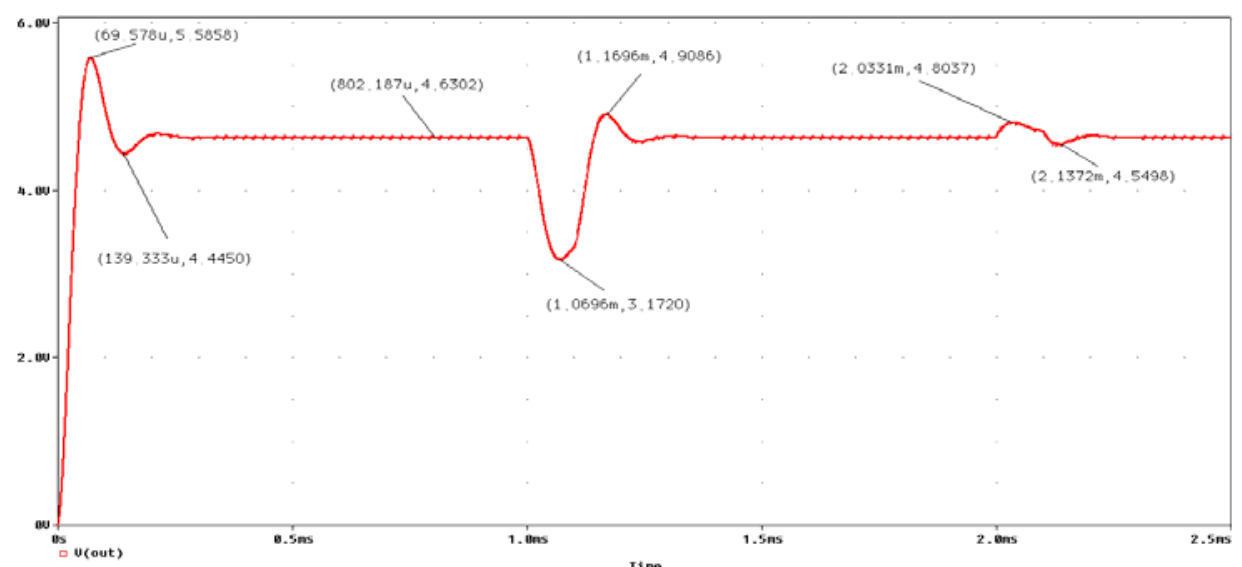

Figure 13. Output voltage with IRF540Mosfet and BAV102 Diode in PSpice

Table 4. Output Voltage Results from PSpice and Matlab Simulation with IRF540 Mosfet and BAV102 Diode

\begin{tabular}{|c|c|c|c|c|}
\hline & $\begin{array}{c}\text { Steady State } \\
\text { Value }\end{array}$ & $\begin{array}{c}\text { Overshoot Peak } \\
\text { Value }\end{array}$ & $\begin{array}{c}\text { Input Voltage } \\
\text { Disturbance }\end{array}$ & Load Disturbance \\
\hline PSpice & $4.63 \mathrm{~V}$ & $5.585 \mathrm{~V}$ & $3.172 \mathrm{~V}$ & $4.8 \mathrm{~V}$ \\
\hline MATLAB & $4.276 \mathrm{~V}$ & $5.522 \mathrm{~V}$ & $2.605 \mathrm{~V}$ & $4.432 \mathrm{~V}$ \\
\hline
\end{tabular}

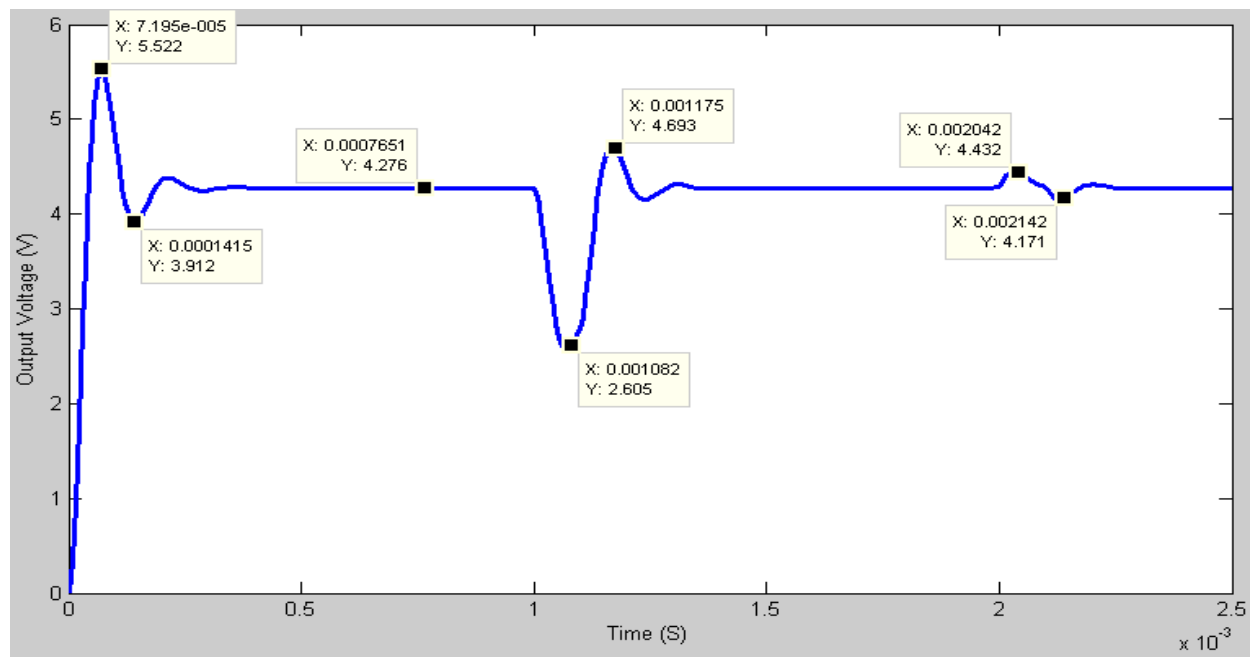

Figure 14. Output voltage with IRF540 Mosfet and BAV102 Diode equivalent models in MATLAB 


\section{Conclusion}

There are a lot of uncertainties in DC-DC converters. Some of the most important uncertainties of these regulators are capacitance and its resistance, inductance and its resistance, resistance of diode and active switch and their conductive voltage drop, resistance and current of load and uncontrollable input voltage. To avoid the complexity of the steady state average model of DC-DC converters, forward voltage drops and on state resistances of diode and mosfet have been neglected generally in regulator modeling. The effects of these parameters on the performance of the system are especially considerable, when the magnitude of the input voltage is low. In this paper, at first an state space average model is presented for buck regulator with all of the above uncertainties. By neglecting some of them, we can easily convert this complete model to any other simple model. Also by converting it to the $P-\Delta-K$ configuration, we can analyze any linear controller by $\mu$-synthesis theorem.

Finally, the buck converter Benchmark circuit is simulated in PSpice and its results are compared with our model simulation results in MATLAB. The results are so closed to each other. In all cases, there is a $1 \mathrm{~V}$ rise in the input voltage at $1 \mathrm{mS}$ and $1 \mathrm{~A}$ change is appeared in load current at $2 \mathrm{mS}$.

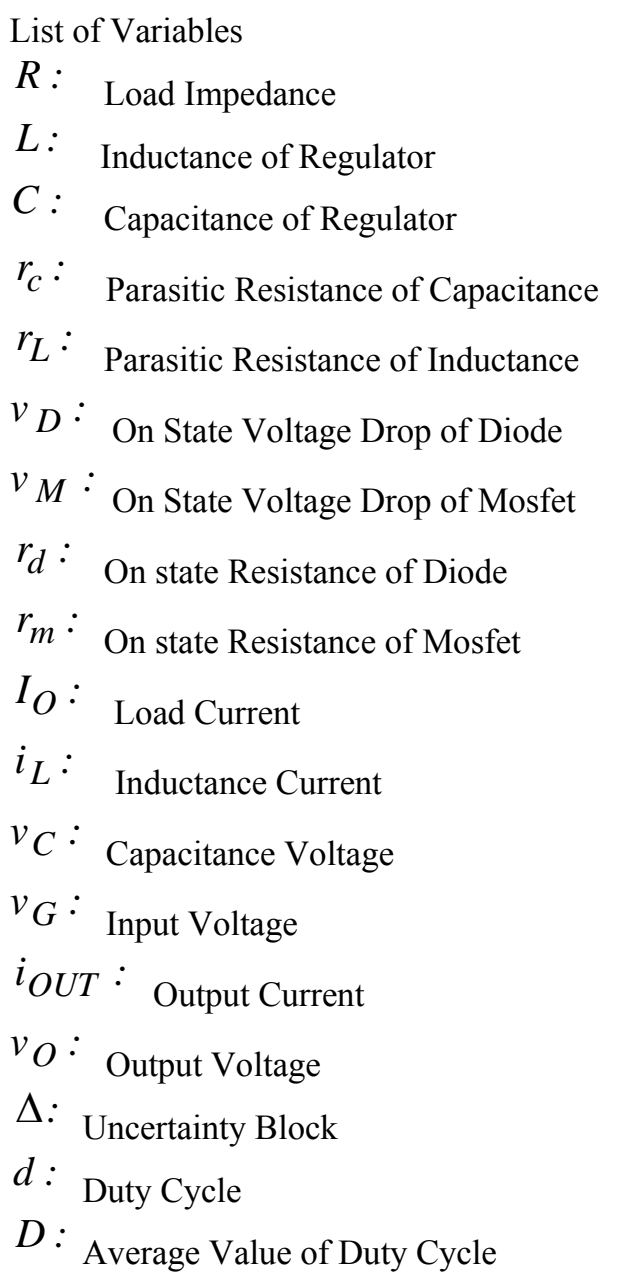




\section{References}

[1] N. Mohan, T. M. Undeland, and W. P. Robbins, "Power Electronics, Converters, Applications, and Design," John Wiley \& Sons, 2003.

[2] R. Erickson,"DC-DC Converter,"Article in Wiley Encyclopedia of Electrical and Electronics Engineering.

[3] J R. B. Ridley,"A New Continuous-Time Model for Current -Mode Control," IEEE Trans. On Power Electronics, Vol. 6, No. 2, PP. 71-280, 1991.

[4] P. Li, and B. Lehman," A Design Method for Paralleling Current Mode Controlled DCDC Converters," IEEE Trans. On Power Electronics, Vol. 19, PP. 748-756, May 2004.

[5] R. D. Middlebrook, and R S.cuk."A General unified Approach to Modeling switching converter power stages," IEEE PESC, Record, PP 18-34, 1976.

[6] F. Alonge, F. D'Ippolito, and T. Gangemi, "Identification and Robust Control of DC/DC Convertor Hammerstein Model", IEEE Transaction on Power Electronics, Vol. 23(Issue6), November 2008.

[7] B. Tamescu, "On the Use of Fuzzy Logic to control Paralleled DC-DC Converters," PHD Thesis, Blackbury, Virginia Polytechnic Institute and State University, October 2001.

[8] A. Towati,"Dynamic Control Design of Switched Mode Power Converters,"Doctoral Thesis, Helsinki Jniversity of Technology, 2008.

[9] R. Naim, G. Weiss, and S. Ben-Yaakov, " $H \propto$ Control Applied to boost Power Converters," IEEE Trans. On Power Electronics, vol. 12, no. 4, pp. 677-683, July 1997.

[10] V. Vorperian, "Simplified Analysis of PWM Converters Using the Model of the PWM Switch,Parts I (CCM) and II (DCM),” Trans. On Aerospace and Electronics systems, vol. 26, no. 3 May 1990.

[11] V. Vorperian,"Fast analytical techniques for Electrical and Electronics Circuits," Cambridge University Press, ISBN 0-521-62442-8, 2004.

[12] A. Romero, "Circuito Integrade de Control Deslizante Para Convertidores Conmutados Continua", Tesis Doctoral (en Realizacion). Department d'Enginyeria Electeronica Universital Polictecnica de Catalunya.

[13] C. M. Ivan, D. Lascu, and V. Popescu," A New Averaged Switch Model Including Conduction Losses PWM Converters Operating in Discontinuous Inductor Current Mode," SER. ElEC ENERG. Vol. 19, No. 2 , PP 219-230, August 2006.

[14] M. R. Modabbernia, A. R. Sahab, M. T. Miezaee, and K. Ghorbani, "The State Space Average Model of Boost Switching Regulator Including All of the System Uncertainties," Advanced Materials Research, Vol.4-3-408, pp 3476-3483, 2012.

[15] M. R. Modabbernia, A. R. Sahab, and Y. Nazarpour, "P- -K Model of Boost Switching Regulator with All of The system Uncertainties Based On Genetic Algorithm," International Review of Automatic Control, Vol. 4, No. 6, November 2011.

[16] M. K. Kazimierczuk, "Pulse-width Modulated DC-DC Power Converters," John Wiley \& Sons, ISBN: 978-0-470-77301-7, 2008.

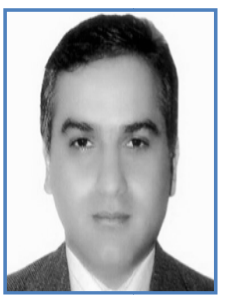

Mohammad Reza Modabbernia was burn in Rasht, IRAN, in 1972. He received the B.S. degree in Electronics Engineering and M.S. degree in control engineering from KNT, the University of Technology, Tehran, IRAN in 19995 and 1998 respectively. He is the staff member of Electronic group of Technical and Vocational university Rasht branch, Rasht, IRAN. His research interests include Robust Control, Nonlinear Control and Power Electronics. 